\title{
Transformations of particles, metal elements and natural organic matter in different water treatment processes
}

\author{
YAN Ming-quan, WANG Dong-sheng*, SHI Bao-you, WEI Qun-shan, \\ QU Jiu-hui, TANG Hong-xiao \\ State Key Laboratory of Environmental Aquatic Chemistry, Research Center for Eco-Environmental Sciences, Chinese Academy of Sciences, \\ Beijing 100085, China.E-mail:wgds@rcees.ac.cn
}

Received 13 March 2006; revised 8 May 2006; accepted 15 May 2006

\begin{abstract}
Characterizing natural organic matter $(\mathrm{NOM})$, particles and elements in different water treatment processes can give a useful information to optimize water treatment operations. In this article, transformations of particles, metal elements and NOM in a pilot-scale water treatment plant were investigated by laser light granularity system, particle counter, glass-fiber membrane filtration, inductively coupled plasma-optical emission spectroscopy, ultra filtration and resin absorbents fractionation. The results showed that particles, NOM and trihalomethane formation precursors were removed synergistically by sequential treatment of different processes. Preozonation markedly changed the polarity and molecular weight of NOM, and it could be conducive to the following coagulation process through destabilizing particles and colloids; mid-ozonation enhanced the subsequent granular activated carbon (GAC) filtration process by decreasing molecular weight of organic matters. Coagulation-flotation and GAC were more efficient in removing fixed suspended solids and larger particles; while sand-filtration was more efficient in removing volatile suspended solids and smaller particles. Flotation performed better than sedimentation in terms of particle and NOM removal. The type of coagulant could greatly affect the performance of coagulation-flotation. Pre-hydrolyzed composite coagulant (HPAC) was superior to $\mathrm{FeCl}_{3}$ concerning the removals of hydrophobic dissolved organic carbon and volatile suspended solids. The leakages of flocs from sand-filtration and microorganisms from GAC should be mitigated to ensure the reliability of the whole treatment system.
\end{abstract}

Key words: flotation; fixed suspended solid; trihalomethane formation potential; ultra filtration; resin absorbent fractionation

\section{Introduction}

Natural water contains a wide variety of impurities, which mainly include clays, organic detritus, algae, microorganisms, as well as some anthropogenic pollutants, such as pesticides and toxic heavy metals. Due to the huge surface area, water particles can adsorb large amount of organic and inorganic matters, and play crucial roles in the transportation and transformation of pollutants. There are many kinds of organic species in natural water, which are of concern to human health. Organic matters can be toxic by themselves or by carrying other harmful contaminants, and more importantly, natural organic matter (NOM) can be precursors of many disinfection by-products (DBPs). In addition, the existence of NOM can interfere some treatment processes and result in performance deterioration. Contaminants from raw water could be removed step-by-step following sequential treatment processes. The selection and arrangement of different treatment processes are of great importance for achieving high contaminant removal efficiency. Thus, it is necessary to characterize the

Project supported by the Hi-Tech Research and Development Program (863) of China (No. 2002AA00601140) and the National Natural Science Foundation of China (No. 50578155, 20477054). *Corresponding author. E-mail:wgds@rcees.ac.cn. contaminants in both raw water and each process effluent to better understand the features of each treatment step and ensure safe drinking water supply.

Characteristics of particles have been extensively studied (Lerman, 1979; Stumm, 1987; Buffle and Leppard, 1995a, b). Turbidity measurement, laser light granularity analysis (LLG), particle countering (PC) and glass-fiber membrane filtration (GFM) are four widely used methods of characterizing particles (VlaSki et al., 1997; Inoue et al., 2004). However, each individual method can give particle related information from different aspects depending on the specific principles it involves. However, with combination of these methods, relatively comprehensive characteristics of particles can be obtained. For instance, GFM is able to tell component in separated particles in water; LLG is powerful for analyzing the granularity distribution during coagulation/flocculation processes; while PC are suitable for detecting fine particle number in postfiltration waters.

NOM is a category of extremely complicated organic matter, and it is currently impossible to characterize it at molecular level. Ultra filtration (UF) and resin absorbents fractionation (RA) are two well accepted methods to characterize NOM (Leenheer and Croue, 2003). 
Variations of NOM between different source waters and between treatment stages in polarity and molecular weight distributions have been reported inconsistently (Chang et al., 2001; Amy et al., 1987; Owen et al., 1995; Marhaba and Van D, 2000; Matilainen et al., 2002; Edwards and Benjamin, 1992). Meanwhile, some common observations exist, including: coagulation removes higher molecular weight and hydrophobic NOM (Dennett et al., 1996; Amy et al., 1992; Jacangelo et al., 1994; Owen et al. 1995); ozonation can convert NOM from humic substances to non-humic fractions and from higher- to lower-MW fractions (Chiang et al., 2002; Owen et al., 1995); granular activated carbon (GAC) can remove intermediate or small humic molecules more efficiently (Johannsen et al., 1993), and therefore ozonation after filtration can result in enhanced adsorption capacity of GAC (Amy et al., 1992).

However, these findings were primarily obtained based on specific treatment units or technologies. Scarce research has been conducted on the systematic and comprehensive evaluations of particle, metal element and NOM transformations within an integrated water treatment processes. Characterizing particles, elements and NOM in different water treatment steps can provide designers and operators with additional insights into process selection, enhancement and possible innovations.

The objectives of this research are to: (1) investigate properties of particles and NOM in raw water; (2) evaluate the transformation of particles and NOM in water treatment processes; (3) compare the efficiencies of solid/liquid separation processes and of coagulants in removing particles and NOM.

\section{Materials and methods}

\subsection{Water samples}

Samples were collected from a pilot-scale facility in a typical Northern-China water treatment plant, and source water of the plant came from the Yellow River. The pilotscale processes were consisted of two parallel systems; the major processes in sequence were pre-ozonation, coagulation with coagulant pre-hydrolyzed composite coagulant (HPAC), flotation or sedimentation, sand filtration, midozonation, GAC and disinfection. The second one was consisted of pre-ozonation, coagulation with coagulant $\mathrm{FeCl}_{3}$ and flotation. Water samples were collected from each stage effluent to evaluate the performances of individual unit operation. The flow rates of both systems were $5 \mathrm{t} / \mathrm{h}$, and ozone dosages were 1.2 and $2.3 \mathrm{mg} / \mathrm{L}$ in preand mid-ozonation, respectively. The coagulant dosages of both systems were $0.08 \mathrm{mmol} / \mathrm{L}$ as $\mathrm{Al}$ or $\mathrm{Fe}$.

\subsection{Particle characteristics}

Turbidity was measured by 2100 NT Turbidimeter. PC were measured by two on-line particle monitor systems (IBR), which were selected to measure particle size larger than $2 \mu \mathrm{m}$ and reported as numbers of eight size ranges: $2-$ $3,3-5,5-7,7-10,10-15,15-20,20-25$, and $>25 \mu \mathrm{m}$. Total suspended solid (TSS), volatile suspended solids (VSS) and fixed suspended solids (FSS) was measured by GFM
(GF/D, $1.0 \mu \mathrm{m}$ nominal pore size), referring to standard methods (APHA, 1998). Volume density percentage was measured by LLG (Mastersizer 2000, British Malvern Co.), which could give the particle distribution in the form of volume/diameter also.

\subsection{NOM characteristics}

Regenerated cellulose membrane (Dia. $63.5 \mathrm{~mm}$, Millipore, USA) with nominal molecular weight cut-off of 30 , 10,3 and 1 kilo Dalton $(\mathrm{kD})$, were used to fractionate NOM sequentially with Amicon Ultrafiltration Cup (Millipore, USA). The applied pressure through the membranes ranged from 250 to $350 \mathrm{kPa}$. The contents of each fraction were determined by analyzing the total organic carbon (TOC) difference between the effluent of each membrane and source water.

Amberlite XAD-8, XAD-4 and anionic exchange resin IRA-958 were used to fractionate NOM according to the procedure of Thurman and Malcolm (1981) and Malcolm and MacCarthy (1986). Water samples were pre-filtered by $0.45 \mu \mathrm{m}$ membrane to remove particles and were introduced to XAD-8 packed Column I; the hydrophobic base and neutral (HoB\&N) fractions would be absorbed by the resin. Backwash the Column $\mathrm{I}$ by $\mathrm{HCl}$ to get hydrophobic base $(\mathrm{HoB})$, and the hydrophobic neutral (HoN) were obtained by subtracting HoB from HoB\&N. The $\mathrm{pH}$ of Column I effluent was adjusted to 2 using $\mathrm{HCl}$ before introducing into Column I again; the second effluent of Column I contained weakly hydrophobic and hydrophilic fractions. The TOC difference of the first effluent and the second effluent from Column I was the hydrophobic acid (HoA). The second effluent of Column I was introduced into XAD-4 packed Column II, the absorbed fraction was weak hydrophobic acid (WHOA) and the effluent was the hydrophilic fraction (Hi). Column II effluent was introduced into IRA-958 packed Column III, and the effluent was hydrophilic neutral (HiN), the fraction retained by Column III was electrical hydrophilic (HiE) organics. The columns were $3 \mathrm{~cm}$ diameter and $30 \mathrm{~cm}$ height glass chromatographic columns with PTFE caps. Water samples were pumped by peristaltic pumps and controlled at flow rate of $100 \mathrm{ml} / \mathrm{min}$.

\subsection{Analytical methods}

TOC was analyzed by TOC-VCPH (Shimadzu, Japan). DOC (dissolved organic carbon) was analyzed by total organic carbon analyzer (Phoenix 8000 System, TekmarDohrman Co., USA) after filtration through $0.45 \mu \mathrm{m}$ membrane. TOC subtracted by DOC was taken as particular organic carbon (POC). $\mathrm{UV}_{254}$ was measured by a UV-Vis 8500 spectrophotometer (Shanghai, China) after filtrated through $0.45 \mu \mathrm{m}$ membrane. $\mathrm{pH}$ was measured by PHS-3C, calibrated before each experiment everyday. Trihalomethane formation precursors (THMFP) was measured by standard methods (APHA, 1998) after incubation for $7 \mathrm{~d}$. Dissolved metal elements were measured after filtration (1.0 $\mu \mathrm{m}$ glass-fiber filters) using inductively coupled plasma-optical emission spectroscopy (ICP-AES), and total metal elements were measured after sample 
digestion by nitric acid. Particulate elements were obtained by subtracting dissolved metal elements from the total metal elements.

\section{Results and discussion}

\subsection{Particle characterization by GFM}

The GFM and TOC analysis indicated that particles in the Yellow River water in autumn were mainly composed of clays and silts, and organics on particle came from contaminant sedimentation rather than bacteria, algae and their detritus. The values of VSS/TSS and POC/VSS were only $15.8 \%$ and $5.84 \%$, respectively, which were rather lower than bacteria, algae and their detritus, about $40 \%$ (Inoue et al., 2004).

\subsubsection{Changes of TSS, VSS and FSS in water treatment processes}

TSS, FSS and VSS could be removed effectively in the water treatment processes, up to $90 \%$, especially in coagulation-flotation and sand-filtration processes. The relative removal ratios of TSS, FSS and VSS for each process are shown in Fig.1, and the values of TSS and $n(n=\mathrm{FSS} / \mathrm{TSS})$ in each process are shown in Table 1. Coagulation-flotation removed FSS more efficiently than VSS, on the contrary, sand-filtration removed VSS more efficiently. A possible explanation of these phenomena is that flocs formed by dissolved and colloidal organic matter was very small and incompact, which could not be removed efficiently by flotation than by sand-filtration.

VSS could be removed efficiently by pre-ozonation and mid-ozonation, while FSS increased in ozonation process-

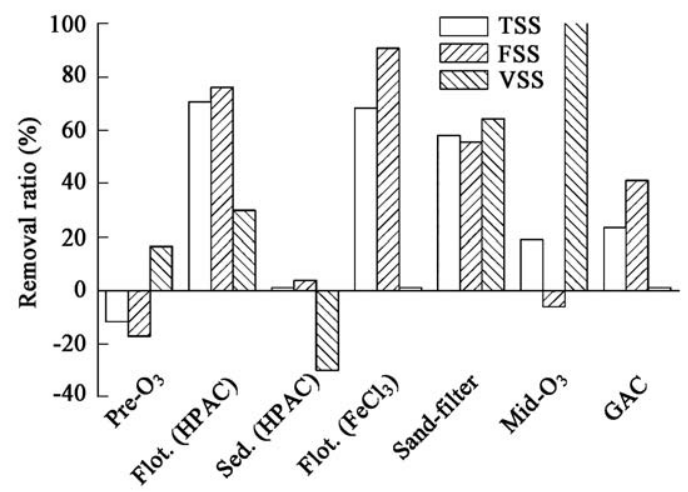

Fig. 1 Removal efficiencies of TSS, FSS and VSS in each water treatment processes. es, especially in pre-ozonation. Moreover, the increase of FSS was more significant than that of TSS (Fig.1). It could be attributed to the destabilization and sedimentation of particles and colloids induced by ozonation (Reckhow et al., 1984; Jekel, 1994).

FSS could be removed efficiently by GAC, while VSS did not change obviously in the process. It might be due to the leakage of microorganisms and metabolizing products from GAC bed (Swietlik, 2004), which will be discussed in the following section.

\subsubsection{Comparison of HPAC vs. $\mathrm{FeCl}_{3}$ and flotation vs. sedimentation}

Coagulants of $\mathrm{FeCl}_{3}$ and HPAC caused great differences in TSS, FSS and VSS removal by flotation. Although the removal efficiencies of TSS in flotation were almost the same for two coagulants, there were great differences between them for FSS and VSS removal (Fig.1 and Table 1). $\mathrm{FeCl}_{3}$ removed FSS more efficiently than HPAC, while HPAC removed VSS more efficiently. Prehydrolyzed composite coagulant HPAC contained high positively charged $\mathrm{Al}$ polymers (e.g. $\mathrm{Al}_{13}$ ), which could not only destabilize dissolved organic matter, organic colloids, but also bridge them to form larger flocs to be removed by flotation (Yan et al., 2006). On the other hand, it was observed that the flocs formed by HPAC were less compact and smaller, which were not favorable for sedimentation, but could be removed more efficiently by flotation.

\subsection{Elements transformation}

\subsubsection{Elements transformation}

Five elements (K, $\mathrm{Ca}, \mathrm{Mg}, \mathrm{Al}$ and $\mathrm{Fe}$ ) were detected simultaneously by ICP-AES in each stage of water treatment processes. The contents of dissolved metal elements were nearly the same during water treatment processes except in the ozonation processes. The contents of dissolved metal elements increased about $1.4 \%$ and $0.6 \%$ in the preozonation and mid-ozonation, respectively, which might be due to the formation of dissolved complex between metal elements and ozonated organic by-products.

The ratio of total metal element content $(\mathrm{K}, \mathrm{Ca}, \mathrm{Mg}, \mathrm{Al}$ and $\mathrm{Fe}$ ) in particle (TMEP) to FSS increased gradually from $9.55 \%$ to $76.89 \%$, except in the pre-ozonation, as shown in Table 1. It was found that Si was the main component in raw water, and which was removed efficiently in water treatment processes. Iron increased $68.04 \%$ and

Table 1 Results of particle analyze in water treatment processes

\begin{tabular}{|c|c|c|c|c|c|c|c|}
\hline & $\begin{array}{l}\text { Turbidity } \\
\text { (NTU) }\end{array}$ & $\begin{array}{c}\text { TSS } \\
(\mathrm{mg} / \mathrm{L})\end{array}$ & $\begin{array}{c}\text { FSS/TSS } \\
(\%)\end{array}$ & $\begin{array}{c}\text { TMEP/FSS } \\
(\%)\end{array}$ & Particle counts & $\begin{array}{l}\text { Density } \\
(\%, \text { vol })\end{array}$ & $\begin{array}{c}\text { Average dia. } \\
(\mu \mathrm{m})\end{array}$ \\
\hline Raw & 12 & 30.4 & 84.21 & 9.55 & 77943 & 0.0032 & 14.9 \\
\hline Pre- $\mathrm{O}_{3}$ & 13.6 & 34.0 & 88.24 & 5.79 & 70421 & 0.0035 & 10.3 \\
\hline Flotation (HPAC) & 1.07 & 10.0 & 72.00 & 7.35 & 5577 & 0.0007 & 16.2 \\
\hline Sedimentation (HPAC) & 6 & 34.0 & 84.71 & 10.97 & 6557 & 0.0059 & 17.8 \\
\hline Flotation $\left(\mathrm{FeCl}_{3}\right)$ & 0.107 & 10.8 & 62.96 & 39.41 & 8013 & 0.0013 & 21.4 \\
\hline Sand-filter & 0.099 & 4.2 & 76.19 & 9.12 & 845 & - & - \\
\hline Mid- $\mathrm{O}_{3}$ & 0.088 & 3.4 & 100 & 18.89 & 908 & - & - \\
\hline GAC & 0.098 & 2.6 & 76.92 & 76.89 & 111 & - & - \\
\hline
\end{tabular}

TSS: total suspended solid; FSS: fixed suspended solids; TMEP: total metal element in particle; GAC: granular activated carbon. 
$259.74 \%$ in pre-ozonation and mid-ozonation respectively because dissolved ferrous iron could be oxidized into insoluble ferric species by ozone. The content of dissolved $\mathrm{Ca}$ decreased $2.5 \%$ and the particulate $\mathrm{Ca}$ increased slightly during mid-ozonation. It could be explained by two possible mechanisms: one was that ozone could break the soluble complexes of $\mathrm{Ca}$ and organic matters, resulting in precipitation; the other was that ozonation might induce the loss of $\mathrm{CO}_{2}$ and subsequent $\mathrm{CaCO}_{3}$ precipitation (Chandrakanth and Amy, 1996).

\subsubsection{Transformations of element $\mathrm{Al}$ in water treatment processes}

Adding coagulant HPAC increased the concentration of total aluminum to a much higher level in effluent of flotation, but the dissolved aluminum only increased slightly. Obviously, most Al was included in the flocs (Fig.2), which could be easily removed by flotation and sand-filtration. In mid-ozonation process, particulate $\mathrm{Al}$ increased from $4.85 \mu \mathrm{g} / \mathrm{L}$ to $25.51 \mu \mathrm{g} / \mathrm{L}$ and dissolved Al decreased from $64.88 \mu \mathrm{g} / \mathrm{L}$ to $37 \mu \mathrm{g} / \mathrm{L}$. It indicated that ozone might be able to destroy the complexes of $\mathrm{Al}$ and humate, resulting in $\mathrm{Al}$ precipitation within the nearly neutral $\mathrm{pH}$ range. The residual dissolved $\mathrm{Al}$ was mainly existed as inorganic species, which could not be removed efficiently by GAC process (Srinivasan and Viraraghavan, 2002). However, residual $\mathrm{Al}$ in the effluent water of GAC could be reached $0.043 \mathrm{mg} / \mathrm{L}$, lower than the water quality standards of China.

Although there were great difference between flotation and sedimentation in particulate Al removal due to their

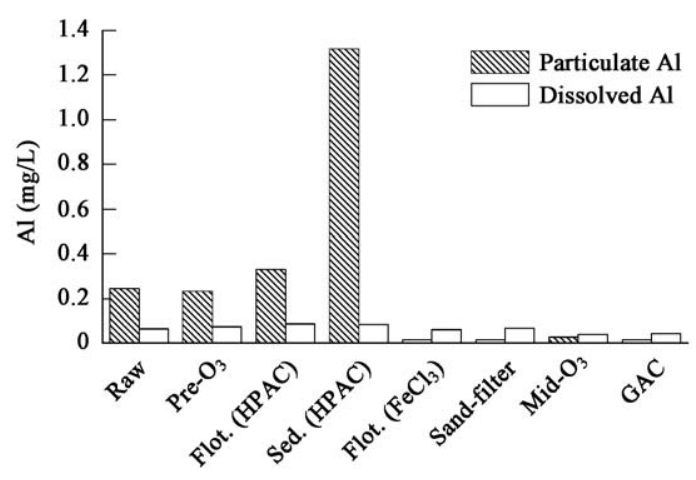

Fig. 2 Transformation of dissolved and particulate $\mathrm{Al}$ in water treatment processes. different efficiencies in particle removal, the content of dissolved $\mathrm{Al}$ was almost the same.

\subsection{Transformations of particle distribution}

Although raw water had been pre-settled in a reservoir, the turbidity was still as high as 12 NTU in autumn. The results of particle diameter distribution are shown in Fig.3. Particle counts in the range of $2-10 \mu \mathrm{m}$ accounted for more than $95 \%$ of those larger than $2 \mu \mathrm{m}$, and the volume/diameter distribution accorded almost to normal distribution with average diameter of $14.9 \mu \mathrm{m}$.

\subsubsection{Transformations of particle distribution in water treatment processes}

Coagulation-flotation, sand-filtration and GAC were the three most efficient stages for particle number removal (Table 1), and all their relative removal ratios were as high as more than $87 \%$.

Ozone could destabilize and aggregate many smaller particles and colloids to form larger ones; on the other hand, ozone could break some larger particles by decomposing some organic components. As presented in Table 1 , after pre-ozonation, TSS, turbidity and volume density increased, meanwhile particle counts reduced $10 \%$, but the percentage of smaller diameter particles increased, and the diameter distribution graph shifted slightly to left (Fig.3a).

Coagulation-flotation was the most efficient stage in removing particles in water treatment processes (Table 1 ), and it removed large diameter particles more efficiently. Although the numbers of each diameter range decreased drastically, the percentage of 2-3 $\mu \mathrm{m}$ particles increased from $40 \%$ to $55 \%$ in coagulation-flotation with coagulant HPAC (Fig.3a). As to the volume distribution corresponding to flotation, the particle percentage with average diameter increased and the distribution became more focalized (Fig.3b).

Sand-filtration removed about $90 \%$ number of particle, and decreased the turbidity from 1.07 NTU to 0.107 NTU. Moreover, the percentage of 2-3 $\mu \mathrm{m}$ particles reduced from $55 \%$ to $37 \%$. Whereas it was observed that the percentage of larger particles increased and such phenomenon was more obvious in summer. It might be resulted from the leakage of some aggregated particles.

Mid-ozonation increased the particle counts and changed particle distribution slightly. The counts of all diameter range particle increased with exception of those
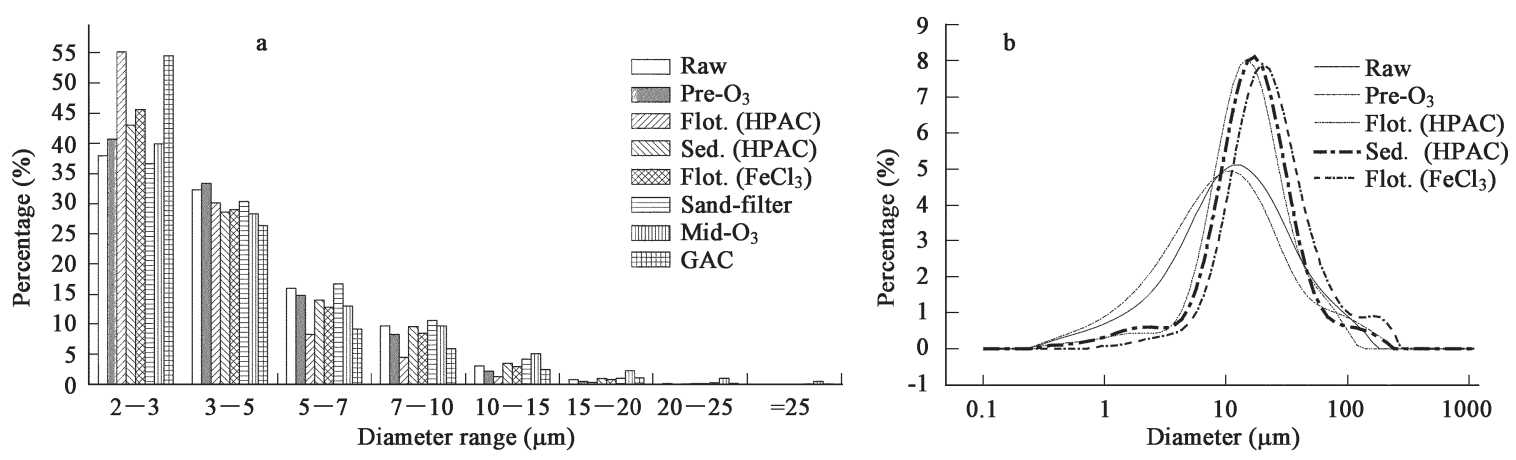

Fig. 3 Particle number distribution (a) and volume distribution (b) in water treatment processes. 
within 3-10 $\mu \mathrm{m}$ diameter ranges, which decreased or kept constant.

GAC removed residual particles efficiently, especially for larger particles, and reduced the turbidity to 0.088 NTU. While the percentage of $2-3 \mu \mathrm{m}$ particle increased from $40 \%$ to $55 \%$, which was distinctly different from sand-filtration.

\subsubsection{Comparison of flotation vs. sedimentation and coagulant HPAC vs. $\mathrm{FeCl}_{3}$}

Flotation was more efficient than sedimentation with coagulant HPAC to remove particles. The particle volume density and counts of sedimentation were $84 \%$ and $17.6 \%$ more than those of flotation, respectively. The flocs formed by coagulant HPAC were small and incompact, which was not favorable for sedimentation. It can be seen that the particle volume distribution graph of flotation is in the left of that of sedimentation and the percentage of small diameter particles of flotation is higher than that of sedimentation. Flotation was relatively more efficient in removing larger particles than sedimentation.

Comparing the efficiency of coagulant HPAC and $\mathrm{FeCl}_{3}$ in particle, the removal was affected by instruments and the quality of flocs. The results of turbidity measurement, particle counts, TSS and volume density did not match well. Generally, it is clear that the average diameter formed by coagulant $\mathrm{FeCl}_{3}$ was greatly larger than that formed by HPAC (Fig.3b).

\subsection{Transformation of DOC and THMFP in water treatment processes}

\subsubsection{Removal of DOC, SUVA and THMFP in water treatment processes}

The organic matter in the Yellow River was mainly in dissolved form. The ratio of particulate organic carbon (POC) to TOC in raw water was only $4.25 \%$ (Thurman, 1985). Fig.4 shows the changes of DOC, SUVA (the sample's UV absorbance at $254 \mathrm{~nm}$ divided by the DOC concentration of the solution) and THMFP (trihalomethanes formation potential) in the water treatment processes. Coagulation-flotation, mid-ozonation, GAC are the most efficient processes in DOC, SUVA and THMFP removal.

The removal ratio of DOC in coagulation-flotation stage with coagulant HPAC was only about $12.3 \%$, whereas the total TOC removal could be higher than the enhanced coagulation standard of USEPA (15\%) with additional $3 \%$

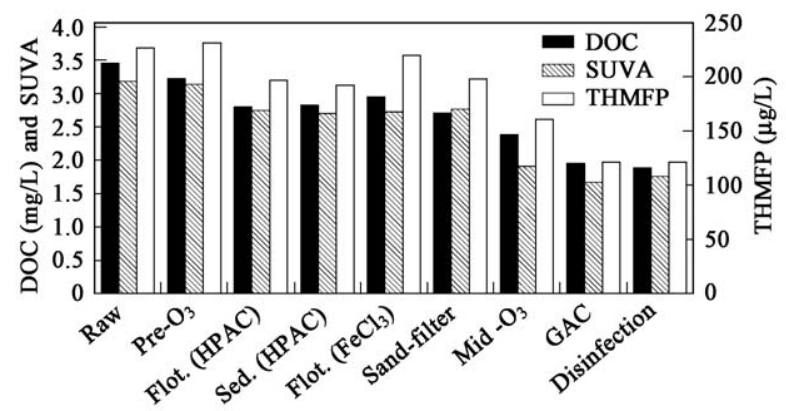

Fig. 4 Transformation of DOC, SUVA and THMFP in water treatment processes.
DOC removed by sand-filtration and $4 \%$ POC removed by coagulation and filtration for this kind of water with high alkalinity (166 mg/L $\left.\mathrm{CaCO}_{3}\right)$, medium TOC (3.4 $\mathrm{mg} / \mathrm{L})$. Flotation and sedimentation achieved similar DOC and SUVA removal when coagulant HPAC was used. On the other hand, coagulant HPAC was more efficient in DOC, SUVA and THMFP removal than $\mathrm{FeCl}_{3}$ during the flotation process.

\subsubsection{Transformations of DOC in water treatment pro- cesses}

The results of resin absorbent and UF fractionations for water treatment processes are shown in Fig.5. The relatively low DOC of raw water indicated that it was polluted slightly by organic matters. It can be seen that the percentage of hydrophobic DOC in raw water was slightly low, but the fraction with molecular weight in the range of 3-10 kD DOC was extremely high (Chiang et al., 2002; Amy et al., 1992; Jacangelo et al., 1994; Edwards and Benjamin, 1992).

Although only about $6.7 \%$ of DOC was removed in preozonation, its characteristics changed obviously and the value of SUVA decreased from 3.13 to 2.74. Ozone can react with polar organic function groups such as double bonds, activated aromatic systems, chained carboxylic acids and non-protonated amine and decompose them. The molecular weight $>30 \mathrm{kD}$ DOC was decomposed completely and the percentage of larger molecular weigh DOC decreased obviously. On the contrary, molecular weigh $<1 \mathrm{kD}$ DOC increased. The reaction mechanism of ozone with NOM is complicated, and it has not been clearly understood up to now. With the Yellow River water, ozone decreased the percentage of hydrophobic acid and hydrophilic electrical fractions greatly, while the percentage of weakly hydrophobic acid and hydrophilic

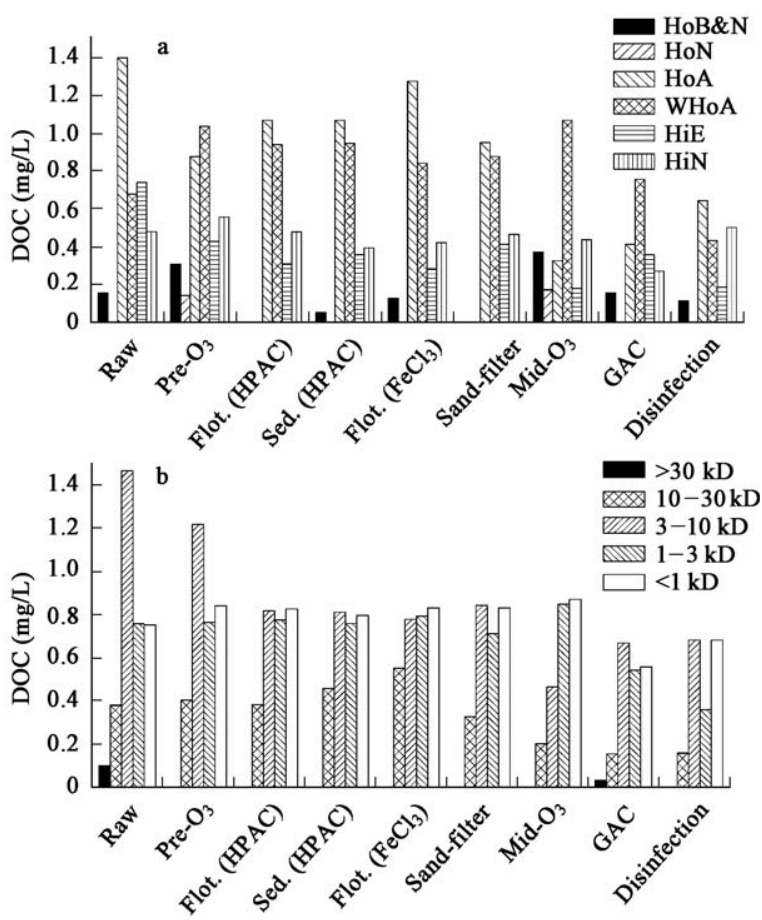

Fig. 5 Transformation of DOC with different polarity (a) and molecular weight range (b) in water treatment processes. 
neutral DOC increased obviously. In addition, the hydrophobic base and hydrophobic neutral fractions also increased. These findings were in agreement with the result of Swietlik (2004). The same DOC transformation tendencies were observed in mid-ozonation stage. With high dosage of $\mathrm{O}_{3}$, mid-ozonation cut down molecular sizes and changed the distribution and polarity of DOC more greatly. The percentages of molecular weight 10 $30 \mathrm{kD}$ and $3-10 \mathrm{kD}$ DOC reduced from $12 \%$ and $31 \%$ to $8.7 \%$ and $20 \%$, respectively. On the other hand, the content of molecular weight $<3 \mathrm{kD}$ DOC increased significantly, which could be removed effectively by following GAC. The content of hydrophobic acid and hydrophilic electrical DOC decreased greatly, while the contents of hydrophobic base, hydrophobic neutral and weakly hydrophobic acid DOC increased (Fig.5a).

Hydrophobic base and neutral DOC, produced in pre-ozonation, were removed effectively by coagulation. Especially, when coagulant HPAC was used, they were almost removed completely. The components of DOC in natural water is complicated, many organic matter molecules are both amphiphilic and amphoteric. During coagulation, hydrophilic and weakly hydrophobic acid DOC could complex with $\mathrm{Al}$ or Fe species to be more hydrophobic (Pornmerenk, 2001; Edwards and Benjamin, 1992), even to form higher molecular weight DOC. Therefore, hydrophilic DOC might be removed more efficient than hydrophobic acid DOC, and intermediate molecular weight between 3-10 kD DOC be removed more efficiently than high molecular weight DOC (Davis and Gloor, 1981; Brian, 1999).

GAC was the most efficient process in DOC removal, especially for low molecular weight DOC produced in mid-ozonation stage, because this fraction of DOC could diffuse and adsorb more easily. Some molecular weight $>30 \mathrm{kD}$ DOC had been found in the effluent, which was removed completely in former processes. It might be due to the leakage of microbes and/or products of metabolism, which could lead to dramatic changes of the polarity distribution, such as the contents of hydrophobic acid and hydrophilic electrical DOC increased obviously (Jacangelo et al., 1994).

Combined disinfectant of chlorine and ammonia was used. Some DOC was oxidized and decomposed by chlorine and the content of DOC reduced 3.8\%. Chlorine decomposed some higher molecular weight DOC into lower one, and resulted in the content of weakly hydrophobic acid and electrical hydrophilic DOC reduced greatly.

\subsubsection{Comparison of flotation vs. sedimentation and coagulant HPAC vs. $\mathrm{FeCl}_{3}$ in DOC characteristics distribution}

Several researchers (Edzwald, 1983; O'Melia et al., 1987; Malley, 1988) found that removal of OM following coagulation and flocculation was independent of the solid/liquid separation process (flotation vs. settling) with $\mathrm{AlCl}_{3}$ and $\mathrm{PACl}$ as coagulants, which was controlled by the coagulation steps. Our results also showed that there was no obvious difference in TOC removal between flotation and sedimentation by $\mathrm{FeCl}_{3}$. However, the solid/liquid separation process was an important factor affecting the efficiency of OM removal in the case of HPAC as coagulant. When using HPAC as coagulant, TOC removal efficiency via single flotation was about $3 \%$ higher than by sedimentation. Flotation removed hydrophobic DOC more efficiently because hydrophobic air bubble is affinitive to hydrophobic DOC. Hydrophobic basic and neutral DOC were almost completely removed by flotation process and the residual DOC with molecular weight $>10 \mathrm{kD}$ DOC, which was obviously less than that by sedimentation as shown in Figs.5a and 5b. Coagulation-flotation with HPAC was capable of removing DOC and VSS more efficiently. HPAC was also more efficient in hydrophobic DOC removal. More hydrophobic humates were destabilized and attached onto flocs, and the surface of flocs of HPAC was more hydrophobic. The hydrophobicity of the surface of HPAC flocs enhanced their removal by hydrophobic air bubbles in flotation. VSS decreased from 4.0 to $2.8 \mathrm{mg} / \mathrm{L}$ in flotation process. In contrast, they increased from 4.0 to $5.2 \mathrm{mg} / \mathrm{L}$ in sedimentation (Yan et al., 2006).

\section{Conclusions}

The transformations of particles, metal elements and NOM were investigated in this article and main conclusions can be drawn as follows.

The water treatment processes were complementary in particles and NOM removal.

Pre-ozonation and mid-ozonation could not only efficiently remove VSS and DOC, but also could change the characteristics of particles, colloid and NOM greatly, such as destabilize colloids and particles, oxidize high molecular weight DOC into lower molecular weight DOC and change hydrophobic acid and electrical hydrophilic DOC into hydrophobic base, hydrophobic neutral, and weakly hydrophobic acid, which could improve the removal efficiencies of following coagulation and GAC, respectively.

Coagulation-flotation removed FSS, THMFP and DOC efficiently, especially hydrophobic DOC and intermediate molecular weight DOC, produced in pre-ozonation. On the contrary, sand-filtration removed VSS more efficiently and DOC inefficiently.

Granular activated carbon was the most efficient stage to remove DOC and THMFP in water treatment processes. Low molecular weight DOC produced in mid-ozonation was more easily removed in the stage, but the leakage of microorganism and metabolized products occurred.

Coagulant HPAC was more efficient in particle, DOC and THMFP removals than coagulant $\mathrm{FeCl}_{3}$ by flotation and no significant increase of residual dissolved $\mathrm{Al}$ in effluent was observed. With utilization of coagulant HPAC, flotation was more efficient in particles and DOC removal than sedimentation.

Acknowledgements: The authors are very grateful to the people who provided full supports to this research. The kind suggestions from the anonymous reviewers are greatly acknowledged. 


\section{References}

Amy G L, Collins M R, Kuo C J et al., 1987. Comparing gel permeation hromatography and ultrafiltration for the molecular weight characterization of aquatic organic matter[J]. J Am Water Works Assoc, 79(1): 43-49.

Amy G L, Sierka R A, Bedessem J et al., 1992. Molecular size distributions of dissolved organic matter[J]. J Am Water Works Assoc, 84(6): 67-75.

APHA, AWWA, WEF, 1998. Standard methods for the examination of water and wastewater [S]. 20th ed. Washington, DC: American Public Health Association.

Bolto B, Abbt-Braum G, Dixon D et al., 1999. Experimental evaluation of cationic polyelectrolytes for removing natural organic matter from water[J]. Wat Sci Tech, 40(9): 71-79.

Bolto B, Dixon D, Eldridge R et al., 2001. Cationic polymer and clay or metal oxide combinations for natural organic matter removal[J]. Wat Res, 35(11): 2669-2676.

Brian B, Gudrun A B, David D et al., 1999. Experimental evaluation of cationic matter in conventional treatment with alum[J]. Wat Sci Tech, 40(9): 71-79.

Buffle J, Leppard G, 1995a. Characterization of aquatic colloids and macromolecules: 1. Structure and behavior of colloidal matters[J]. Environ Sci Technol, 29(9): 2169-2175.

Buffle J, Leppard G, 1995b. Characterization of aquatic colloids and macromdecules: 2. Key role of physical structures on analytical results[J]. Environ Sci Technol, 29(9): 21762184.

Chandrakanth M S, Amy G L, 1996. Effects of ozone on the colloidal stability and aggregation of particles coated with natural organic matter[J]. Environ Sci Technol, 30(2): 431442.

Chang E E, Chiang P C, Ko Y W et al., 2001. Characteristics of organic precursor and their relationship with disinfectation by-products[J]. Chemosphere, 44: 1231-1236.

Chiang P C, Chang E E, Liang C H, 2002. NOM characteristics and treatabilities of ozonation processes[J]. Chemosphere, 46: 929-936.

Davis J A, Gloor R, 1981. Adsorption of dissolved organics in lake water by aluminum oxide. Effect of molecular weight[J]. Environ Sci Technol, 15(10): 1223-1229.

Dennett K E, Amirtharajah A, Moran T F et al., 1996. Coagulation: Its effect on organic matter[J]. J Am Water Works Assoc, 88(4): 129-142.

Edwards M, Benjamin M M, 1992. Transformation of NOM by ozone and its effect on iron and aluminum solubility[J]. J Am Water Works Assoc, 84(6): 56-66.

Edzwald J K, 1983. Coagulation-sedimentation-filtration processes for removing organic substances from drinking water. Control of organic substances in water and wastewater (Berger B. B., ed.)[C]. USEPA, EPA-600/8-83-011, Washington, D.C.

Inoue T, Matsui Y, Terada Y et al., 2004. Characterization of microparticle in raw, treated, and distributed water by means of elemental and particle size analyses[J]. Wat Sci Tech, 50: 71-78.

Jacangelo J G, DeMarco J, Owen D M et al., 1994. Selected processes for removing NOM: An overview[J]. J Am Water Works Assoc, 87(1): 64-77.

Jekel M R, 1994. Flocculation effects of ozone[J]. Ozone Sci Eng, 16(1): 55-66.

Johannsen K, Assenmacher M, Kleiser M et al., 1993. Influence of the molecular size on the adsorbability of humic substances[J]. Vom Wasser, 81: 185-196.
Leenheer J A, 1981. Comprehensive approach to preparative isolation and fractionation of dissolved organic carbon from natural waters and wastewaters[J]. Environ Sci Technol, 15(5): 578-587.

Leenheer J A, Croue J P, 2003. Characterizing aquatic dissolved organic matter[J]. Environ Sci Technol, 37(1): 18A-26A.

Lerman A, 1979. Geochemical processes-water and sediment environments[M]. New York: Wiley-Interscience.

Lin C F, Liu S H, Hao O, 2001. Effect of functional groups of humic substances on UF performance[J]. Wat Res, 35(10): 2395-2402.

Malcolm R L, MacCarthy P, 1986. Limitations in the use of commercial humic acids in water and soil research[J]. Environ Sci Technol, 20(9): 904-911.

Malley JP Jr, 1988. A fundamental study of dissolved air flotation for treatment of low turbidity waters containing natural organic matter[D]. Dissertation for Ph.D, Department of Civil Engineering, University of Massachusetts, Amherst. 35-60.

Marhaba T F, Van D, 2000. The variation of mass and disinfection by-product formation potential of dissolved organic matter fractions along a conventional surface water treatment plant[J]. Journal of Hazardous Materials, 74(3): 133-147.

Matilainen A, Lindqvist N, Korhonen S et al., 2002. Removal of NOM in the different stages of the water treatment process[J]. Environmental International, 28(6): 457-465.

O'Melia C R, Yao K, Gray K et al., 1987. Raw water quality, coagulant selection, and solid-liquid separation[C]. Presented at the 1987 AWWA Annual Conference Seminar on Influence of Coagulation on the Selection, Operation, and Performance of Water Treatment Facilities, Kansas City, MO, June 14.

Owen D, Amy G, Chowdhury Z et al., 1995. NOM characterization and treatability[J]. J Am Water Works Assoc, 87(1): 46-63.

Pornmerenk P, 2001. Adsorption of inorganic and organic ligands onto aluminum hydroxide and its effect[D]. Dissertation for Ph.D, Department of Environmental Engineering, Old Dominion University, Norfolk. 18-43.

Reckhow D A, Singer P C, 1985. Mechanisms of organic halide formation during fulvic acid chlorination and implications with respect to preozonation[C]. In: Water Chlorination: Chemistry, Environmental Impact and Health Effects. Chelsea, MI: Lewis Publishers. 5:1229-1257.

Schäfer A I, Mauch R, Fane A G et al., 2002. Charge effects in the fractionation of natural organics using ultrafiltration[J]. Environ Sci Technol, 36(12): 2572-2580.

Srinivasan P T, Viraraghavan T, 2002. Characterization and concentration profile of aluminum during drinking-water treatment[J]. Water S A, 28(1): 99-106.

Stumm W, 1987. Aquatic surface chemical[M]. New York: Wiley Inter Science.

Swietlik J I, 2004. Reactivity of natural organic matter fractions with chlorine dioxide and ozone[J]. Wat Res, 38: 547-558.

Thurman E M, 1985. Organic geochemistry of natural waters[M]. The Netherlands: Dordrecht.

Thurman E M, Malcolm R L, 1981. Preparative isolation of humic substances[J]. Environ Sci Technol, 15(5): 463-466.

VlaSki A, van Breemen A N, Alaerts G J, 1997. The role of particle size and density in dissolved air flotation and sedimentation[J]. Wat Sci Tech, 36(4): 177-189.

Yan M Q, Wang D S, You S J et al., 2006. Enhanced coagulation in a typical north-china water plant[J]. Wat Res, 40(19): $3621-3627$. 